Review

\title{
A Review of Forest Ecosystem Vulnerability and Resilience: Implications for the Rocky Desertification Control
}

\author{
Haiyan Liu, Kangning Xiong *, Yanghua Yu, Tingling Li, Yao Qing, Zhifu Wang and Shihao Zhang
}

\section{check for}

updates

Citation: Liu, H.; Xiong, K.; Yu, Y.; Li, T.; Qing, Y.; Wang, Z.; Zhang, S.

A Review of Forest Ecosystem

Vulnerability and Resilience:

Implications for the Rocky

Desertification Control. Sustainability

2021, 13, 11849. https://doi.org/

$10.3390 /$ su132111849

Academic Editors: Baojie He,

Ayyoob Sharifi, Chi Feng and

Jun Yang

Received: 10 October 2021

Accepted: 25 October 2021

Published: 27 October 2021

Publisher's Note: MDPI stays neutral with regard to jurisdictional claims in published maps and institutional affiliations.

Copyright: (c) 2021 by the authors. Licensee MDPI, Basel, Switzerland. This article is an open access article distributed under the terms and conditions of the Creative Commons Attribution (CC BY) license (https:/ / creativecommons.org/licenses/by/ $4.0 /)$.
School of Karst Science, State Engineering Technology Institute for Karst Desertification Control, Guizhou Normal University, Guiyang 550001, China; lhy1679454421@163.com (H.L.); yuyanghua2003@163.com (Y.Y.); tinglingli2021@163.com (T.L.); qin333yao444@163.com (Y.Q.); wzfkst@163.com (Z.W.); sh_zhang1993@163.com (S.Z.)

* Correspondence: xiongkn@163.com

\begin{abstract}
With a changing climate and socio-economic development, ecological problems are increasingly serious, research on ecosystem vulnerability and ecological resilience has become a hot topic of study for various institutions. Forests, the "lungs of the earth", have also been damaged to varying degrees. In recent years, scholars have conducted numerous studies on the vulnerability and resilience of forest ecosystems, but there is a lack of a systematic elaboration of them. The results of a statistical analysis of 217 related documents show: (1) the number of studies published rises wave upon wave in time series, which indicates that this area of study is still at the stage of rising; (2) the research content is concentrated in four dimensions-ecosystem vulnerability assessment, ecosystem vulnerability model prediction, ecological resilience, and management strategies-among which the ecosystem vulnerability assessment research content mainly discusses the evaluation methods and models; (3) the research areas are mainly concentrated in China and the United States, with different degrees of distribution in European countries; and (4) the research institutions are mainly the educational institutions and forestry bureaus in various countries. In addition, this paper also reveals the frontier theory of forest ecosystem vulnerability and resilience research from three aspectstheoretical research, index system, and technical methods-puts forward the problems of current research, and suggests that a universally applicable framework for forest ecosystem vulnerability and resilience research should be built in the future, and theoretical research should be strengthened to comprehensively understand the characteristics of forest ecosystems so that sustainable management strategies can be proposed according to local conditions.
\end{abstract}

Keywords: ecosystem vulnerability; ecological resilience; forest; review

\section{Introduction}

Forests, which play a key role in the global carbon cycle, are an important part of the global biosphere [1]. As the mainstay of terrestrial ecosystems and an important renewable resource, forests provide a wide range of ecosystem services to humans [2], not only providing timber and forest products, but also rich species and genetic diversity, which can regulate climate, prevent soil erosion, and suppress wind and sand damage, etc., which plays an extremely significant role in human survival and development [3]. The value created by global ecosystems is estimated to be around USD 33 trillion per year [4]. However, under the influence of natural factors and human disturbances, including climate change, drought, storms, insect invasion, fire, and deforestation [5-10], forest ecosystems have been damaged to varying degrees. For example, selective human logging has reduced vegetation canopy cover and posed a significant threat to soil erosion, then leading to a reduction in the ecological resilience of forests, which in turn presents greater vulnerability [11]. In 2015, Article 5 of the United Nations Framework Convention on Climate Change (UNFCCC) Paris Agreement highlighted the central role of forest ecosystems in achieving the goal of limiting temperature rise objectives and encouraged Parties to manage and protect forest 
ecosystems, recognizing the importance of forest ecosystems in terms of their potential to mitigate climate change and achieve non-carbon benefits [12]. Therefore, it is scientifically important to capture the vulnerability and improve the resistance and resilience of the forest ecosystem.

The concept of vulnerability was first used in the social sciences and is now more commonly applied in ecological research [13]. The ecosystem vulnerability was first introduced to research by the American scholar Clements in 1905 [14]. Later, Niu [15] redefined Ecotone as the "interface" between two or more material, energy, structural, and functional systems in an ecosystem, and the spatial domain of the "transition zone" that extends outwards around the interface, which is called the ecosystem vulnerability zone. At the beginning of the 21st century, the IPCC third assessment report defined vulnerability in the context of climate change as "The degree to which a natural or social system is vulnerable or incapable of coping with the adverse effects of climate change as a function of the characteristics, magnitude and rate of change of a system's climate and its sensitivity and adaptive capacity" [16] and Turner et al. [17] defined vulnerability as a function of the exposure, sensitivity, and adaptive composition of a system under stress. Most current research follows the IPCC definition and considers that the basic components of vulnerability research include the assessment of system change, the evaluation of the sensitivity of the system to respond to change, the estimation of the potential impact of change on the system, and the evaluation of the system's adaptability to change and its possible impacts.

In the mid-nineteenth century, along with the development of western industry, 'resilience' was mainly used in mechanics to describe the ability of metals to recover after deformation by external forces [18]. It was not until the 1970s that Canadian scholar Holling [19] first introduced the concept of resilience to the field of ecology; in the 1980s and 1990s, ecological resilience was considered as the ability of complex systems to absorb external shocks and ensure the continuation of the original functions and structures of the system, thus stimulating thoughts on how to make systems more resilient and stronger by allowing them to absorb greater external shocks [20]; subsequently, Gunderson and Holling [21] proposed the Panarchy model of ecosystem evolutionary dynamics and a multiscale nested adaptive cycle model with core concepts describing the adaptive evolution of complex systems, a time-space-conscious hierarchical order, and adaptive cycles. Liao [22] argues that ecological resilience does not need to take into account changes in the state of the system, but should indicate the system's ability to survive; based on previous research, George et al. [23] argues that ecological resilience is the system's ability to adapt and recover in the face of external disturbances, and that its maintenance is a key objective of ecological restoration; a further conceptualization sees ecological resilience as emphasizing the need for systems to reach new and diverse states of equilibrium with the ability to adapt and change to transform to these different states [24].

The study of forest ecosystem vulnerability and ecological resilience has important implications for revegetation and sustainable forest management. Forest ecosystems are inherently resilient, and many species and ecosystems have already adapted to historically changing climatic conditions, but the scale and rate of future change may exceed the natural adaptive capacity of forest species and ecosystems [25]. Including the current global warming has caused many changes in forests [26], such as droughts that have increased forest wood mortality [27], and these changes may be exacerbated by responses to human activities, such as the introduction of exotic pests, habitat destruction, and fires [28], resulting in forest ecosystem vulnerability. Ecosystem vulnerability studies are an important tool for capturing the state and spatial distribution characteristics of regional habitat vulnerability [29] however, studies of vulnerability vary by region and by genesis, limiting the general applicability of the concept of vulnerability and comparisons between different domains. In addition, ecological resilience is a concept closely related to ecosystem vulnerability, which is often quantified as the recovery time of a system after a disturbance [30]. However, current research lacks a general framework for linking vulnerability and resilience [31]. 
Additionally, although resilience is currently widely considered in forests, it has not been widely implemented in forest research and management [32]. Vulnerability studies can therefore be conducted to identify risks arising from future changes and to identify key vulnerable resources; resilience studies can address the uncertain future of forestry by quantifying the resilience of systems to disturbance, thus providing guidance for enhancing the ecological services of forests.

This study provides a comprehensive analysis of existing research on forest ecosystem vulnerability and ecological resilience, and classifies the literature according to annual distribution, research content, research areas, and institutions. It summarizes the current domestic and international research progress and main achievements related to ecosystem vulnerability and ecological resilience, proposes nine key scientific questions to provide directions for future research on forest ecosystem vulnerability and ecological resilience, and provides a theoretical basis for the current enhancement of forest ecosystem functions under the rocky desertification control in karst areas.

\section{Acquisition and Argumentation of Literatures}

In order to understand the current state of research on the vulnerability and resilience of forest ecosystems. In this paper, the English-language literature is from the "Web of Science" database, which has extensive and multidisciplinary bibliographic data on cuttingedge scientific publications, and this database is commonly used for academic research and bibliometric analysis in the field [33,34]; the Chinese literature is from "China National Knowledge Infrastructure". The aim of the literature search was to focus on the research theme of vulnerability and resilience of forest ecosystems, with the terms "vulnerability" and "resilience" used to express theoretical knowledge related to the ecological field. Therefore, the first search was conducted using "topic" as the search term and "forest" as the first search word; among the results, "Ecological/Ecosystem vulnerability" and "Ecological/Ecosystem resilience" were used as the search words for the second search; the search time range was the maximum time range of the database.

Through an initial review of article titles, abstracts, and keywords, the screened articles focused on forest ecosystems and associated systems (e.g., tree species and forest-dependent communities) and explicitly examined concepts, methods, and models of vulnerability and resilience; we also accepted studies that provided methods for assessing vulnerability and resilience of non-specific ecosystems, as they apply to forests as well. Then, the full text was further screened to eliminate duplicates, and 217 articles were finally selected for review, including 61 in Chinese journals and 156 in English journals. Among them included 197 journal articles, 13 master's theses, 5 doctoral theses, and 2 conference articles. Microsoft Excel 2016 was used to analyze the trend of the number of publications and, at the same time, the statistical analysis function that comes with the Web of Science and CNKI systems was used to statistically analyze the time, country, and institution of publications collected. This paper systematically analyses the literature on forest ecosystem vulnerability and resilience; summarizes main research results and landmark achievements in three aspects, including basic theory, indicator systems, and technical methods; and proposes key scientific questions based on existing research, in order to provide a scientific basis for future research on forest ecosystem vulnerability and resilience, promote forest ecosystem conservation and sustainability, and ultimately achieve harmonious development between humans and nature.

\subsection{Annual Distribution of the Literature}

As shown in Figure 1, domestic and international research on forest ecosystem vulnerability and resilience can be roughly divided into three stages. The first stage was from 1996 to 2008, with a relatively small fluctuation in the curve and no more than five publications per year, as it was an embryonic stage; at the second stage (2008-2014), the number began to grow slowly and the curve showed a relatively large increase; in the third stage (2014-2021), the curve rose rapidly and the number of publications showed a 
substantial increase, reaching the highest level in 2020. Overall, English literature follows much the same trend as the overall literature, while the Chinese literature is smaller.

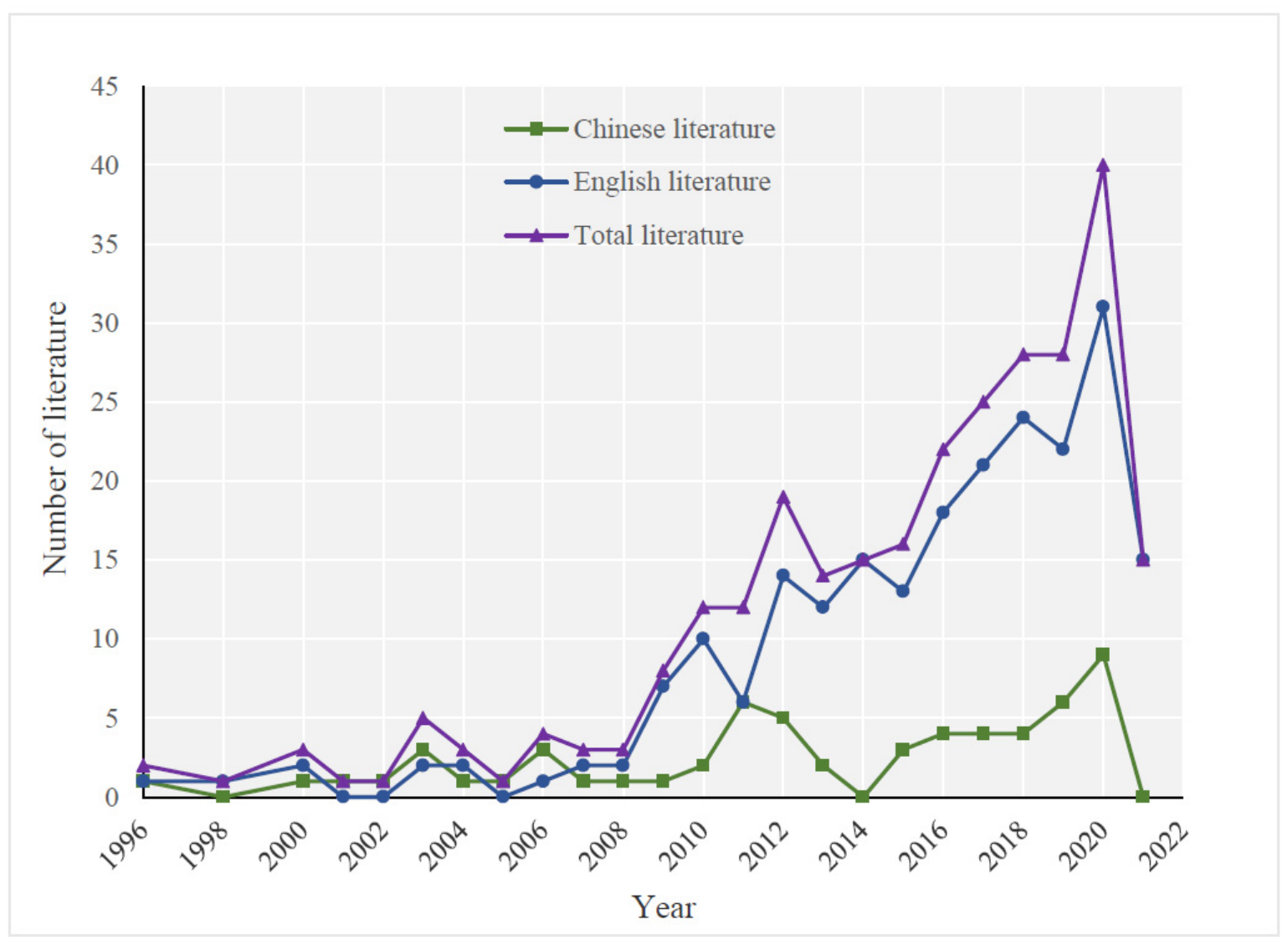

Figure 1. Trends in the literature related to ecosystem vulnerability and ecological resilience research of forest ecosystem by year until 2021.

\subsection{Content Distribution of the Literature}

The content of forest ecosystem vulnerability and resilience research is shown in Figure 2, which divides all literature into ecosystem vulnerability assessment, modelling prediction of ecosystem vulnerability, ecological resilience, management strategies, and other types, according to their research content. The ecosystem vulnerability assessment literature accounted for $36.74 \%$ and its modelling prediction category accounted for $9.77 \%$. Ecosystem vulnerability research includes theoretical studies, indicator system construction, evaluation methods, and modelling prediction, among which evaluation methods and indicator system construction are the mainstream, while modelling prediction is an emerging element of ecosystem vulnerability research in recent years [6,35]. Ecological resilience research accounts for $34.42 \%$, with studies mainly aiming to enhance system resistance and reduce system vulnerability [36,37]. Management strategies accounted for $12.56 \%$ and other types of literature accounted for $6.51 \%$. Overall, there is a predominance of research on forest ecosystem vulnerability and resilience, but it is mostly independent and less theoretical research.

\subsection{Country Distribution of the Literature}

The literature regions are organized as shown in Figure 3. Due to spatial constraints, only regions with more than three articles are listed in this article. Studies on the vulnerability and resilience of forest ecosystems are dominated by China and the United States, accounting for $25 \%$ and $18 \%$ of the overall studies, respectively. China has conducted studies to varying degrees in the northwest desert belt, the northeast forest-grass interlacing 
belt and the southwest karst-karst fragile belt, followed by Canada, Germany, Spain, Australia, Brazil, and France, with Canada accounting for $7 \%$, Germany accounted for $6 \%$. The rest of the countries, including the UK, India, and Switzerland, also have a small number of studies. Overall, most of the study areas are located in temperate, tropical, and subtropical regions. Additionally, they are concentrated in Asia (China), North America (USA, Canada, etc.), and Europe (Germany, Spain, etc.). There are fewer studies of vulnerable areas of karst rocky desertification.

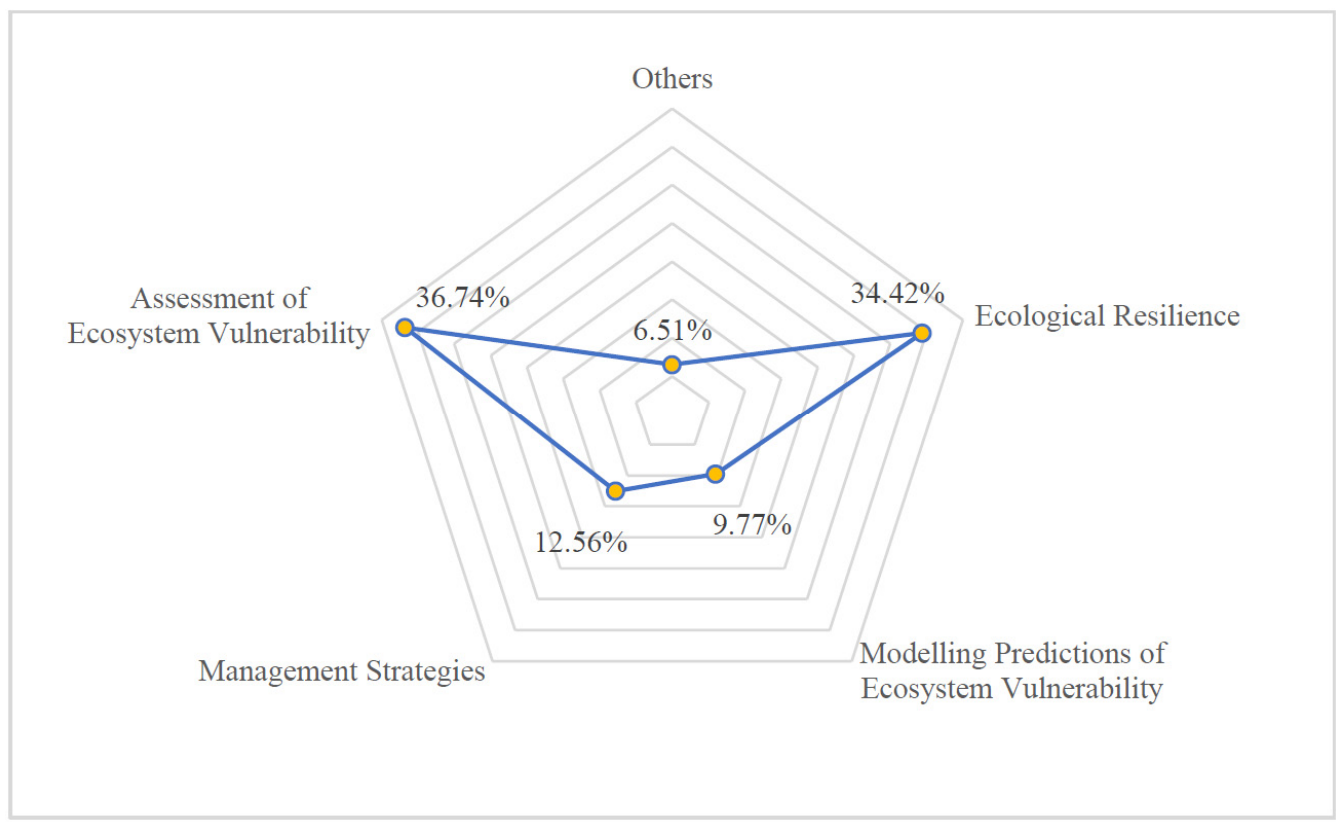

Figure 2. Literature by content.

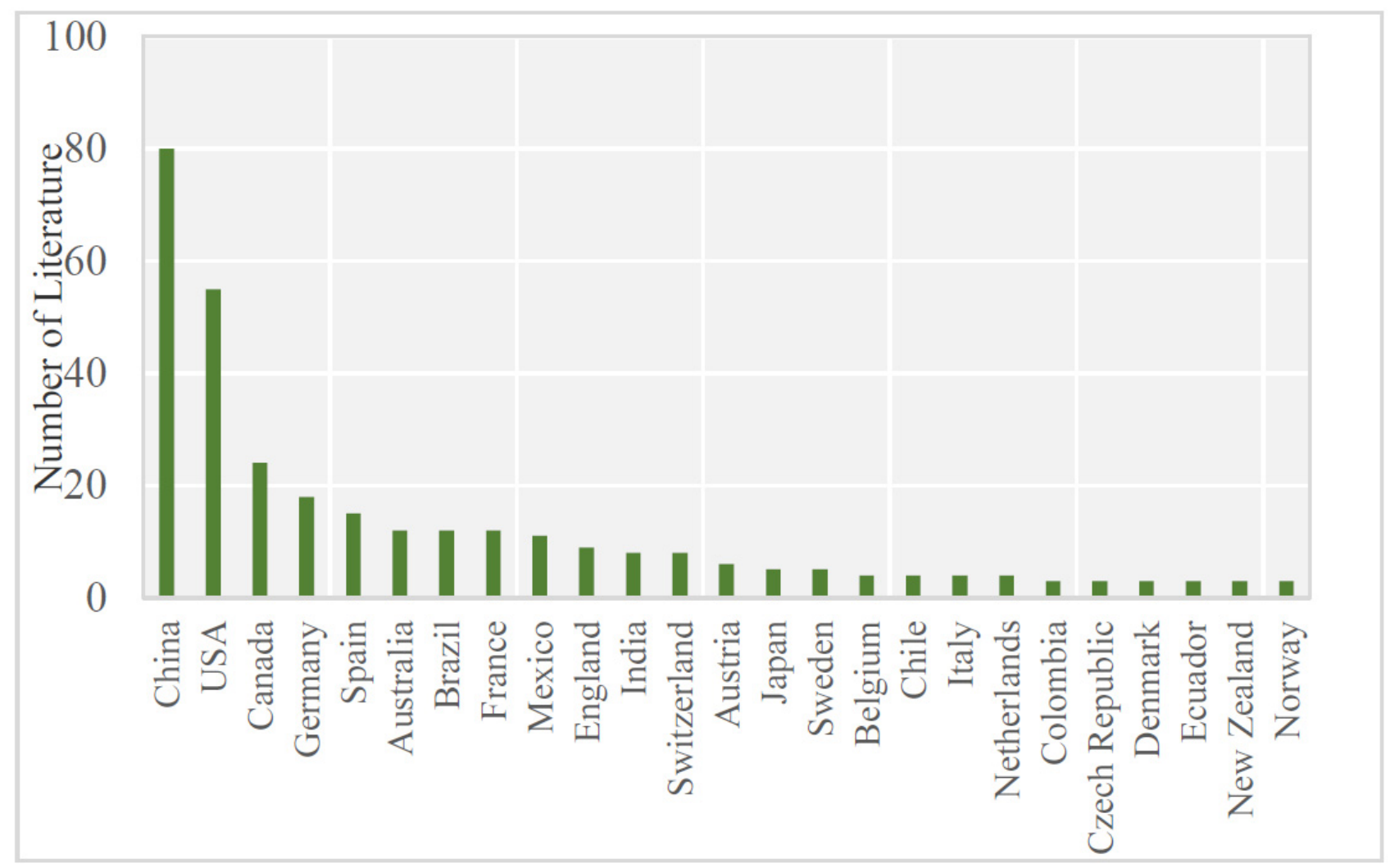

Figure 3. Literature by country. 


\subsection{Institution Distribution of the Literature}

A count of all the literature reveals a wide range of research units. Due to the length of the chart, only units with three or more articles were counted, with a total of 118 articles and 23 units (Figure 4). Among them, the United States Forest Service has the largest number of publications, with a cumulative total of 13, and Beijing Forestry University has 11, followed by the United States Geological Survey, Technical University of Munich, University of Minnesota System, University of Wisconsin Madison, University of Vermont, and University of Nacional Autonoma de Mexico. All the research units, except in China, are mostly institutions of higher education or forestry in developed countries, such as the United States of America and Germany.

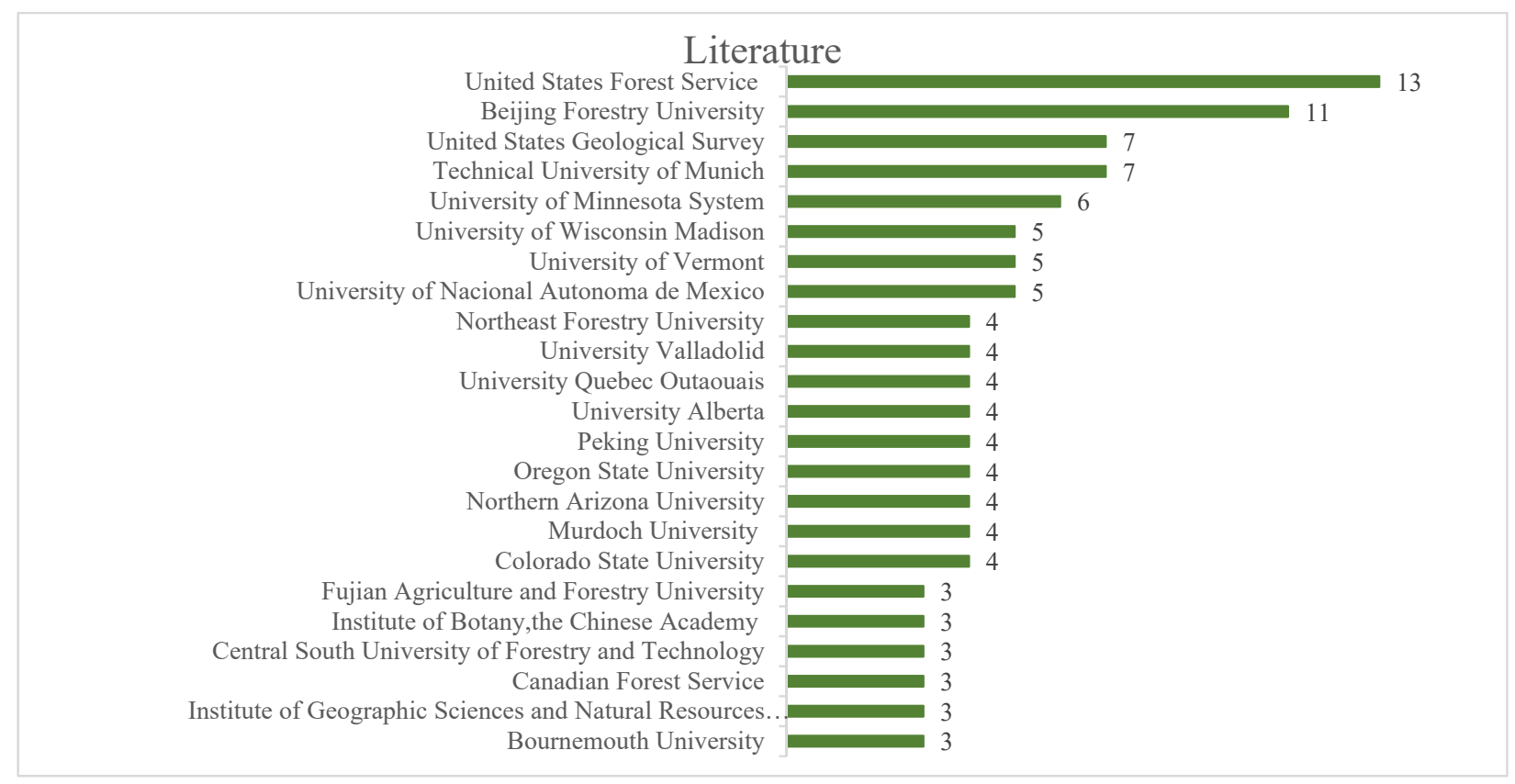

Figure 4. Literature by institution.

\section{Main Progress and Landmark Achievements}

\subsection{Theoretical Research}

3.1.1. The Study of Ecosystem Vulnerability Theory Consists Mainly of the Conceptual Study of Vulnerability, the Analysis of Its Causes, and the Classification of Vulnerability Types

Following the introduction of the concept of ecotone by Clements in 1905 [14], the concept of vulnerability was first introduced and elaborated by Timmerman in the early 1980s in the field of geography, where he argued that vulnerability was an indication of the degree of response within a system to disturbances from hazardous events both within and outside the system [38], followed by a large number of studies which have been conducted on the meaning of ecosystem vulnerability. The study of ecosystem vulnerability covers a wide range of fields and subjects, and the meaning of ecosystem vulnerability varies from one subject to another. The vulnerability of forest ecosystems refers to the combination of natural and anthropogenic factors that cause the structure and function of forest ecosystems to shift in the opposite direction from their original stable state or direction of succession in a certain spatial and temporal context, resulting in the destruction of their basic structure and the weakening of their stability and resilience [39]. For example, forest fire vulnerability is also defined as the potential loss from fire, including impacts on property, people, and environmental stability [40]. Additionally, for drought-induced forest vulnerability, Mildrexler et al. [41] defined its ecosystem vulnerability based on the processes of water and energy exchange due to drought and high temperatures. The vulnerability of forests 
in karstic desertification areas is reflected in the low vegetation cover, the predominance of secondary forest vegetation, the poor water-holding capacity of the soil itself, the looseness of the soil, and the homogeneous mix of species [42]. Different ecologically vulnerable areas have different causes of ecosystem vulnerability, early studies on forest ecosystem vulnerability were mainly based on global climate change [43] and natural disasters [44], but as research progressed, it began to expand to ecosystem vulnerability caused by a combination of anthropogenic and natural disturbances, and the research field was gradually extended from the initial natural ecosystem to the field of research has gradually extended from the initial study of natural ecosystems to the integrated study of social and natural systems.

3.1.2. Ecologists Generally Accept That the Concept of Ecological Resilience Includes the Concept of "Engineering and Ecological Resilience", but There Is No Consensus on How to Define or Apply Resilience in a Forestry Context

There has been considerable debate on the concept of ecological resilience, including "engineering, ecological and socio-ecological resilience" [45]. However, ecologists generally agree on two definitions of resilience: one focuses on the return to its equilibrium state after a disturbance, usually measured by the rate of recovery, which is often called "engineered resilience" [46]. The second focuses on the ability of a system to maintain its current state, defined as the extent to which a system can tolerate or resist disturbances without or before rearranging into another functionally and structurally different state, also known as "ecological resilience" $[19,21]$. Hodgson et al. [47] argue that both types of resilience are important in most ecological studies and that they should be considered together. For ecological resilience in forest ecosystems, Thompson et al. [48] consider it to be the ability of trees to resist disturbance and to recover to their original state after disturbance. The study of tree ecological resilience is a necessary element in the study of forest dynamics in the context of frequent times of extreme disturbance [49], for example, drought can make a difference to the growth recovery process of trees by affecting their ecological resilience [50]. The relevance of existing resilience concepts to forest management has also been reviewed [51], but to date there is no consensus on how to define or apply resilience in the context of forestry.

\subsection{Indicator System}

\subsubsection{Ecosystem Vulnerability Assessment Indicator System}

The establishment of an indicator system is the basis for ecosystem vulnerability and resilience assessment, and the construction of the indicator system is mainly reflected in three dimensions: firstly, in view of the regional differences in the formation of ecosystem vulnerability, the dominant factors leading to regional environmental vulnerability are clarified in the light of regional characteristics, and a single-type indicator system is constructed for regional vulnerability. For example, Yu and Lu [52] selected erosionrelated water erosion factors and wind erosion factors to establish an indicator system for vulnerability assessment of the alpine region of the Qinghai-Tibet Plateau; the single-type indicator system is simple in structure, targeted, and has a strong regional dimension, and can identify key factors that lead to regional environmental vulnerability according to regional characteristics.

The second is to combine natural-social-economic aspects, taking into account both the intrinsic structure and functional characteristics of the system, as well as external disturbances, to build a comprehensive indicator system. Currently, scholars are using the "stress-state-response (PSR)" [53], which is based on the idea of cause and effect, and the "exposure-sensitivity-adaptability (VSD)" [54], which is based on the idea of "traitability". These conceptual models have been used to develop indicator systems, such as the work by Cinco-Castro and Herrera-Silveira [55], which constructs an indicator system for mangrove vulnerability in Mexico based on exposure, sensitivity, and adaptability. Comprehensive evaluation indicator systems contain a wide range of indicators, but are less operational due to the limitations of data availability and correlation between indicators [56]. 
The third is to predict the ecosystem vulnerability of systems in a changing future by establishing a simulation-based indicator system in the context of ecosystem vulnerability due to climate change or other changes. This includes climate change modelling, ecosystem modeling, socio-economic development modeling, and land use change modeling [57]. For example, Turkes et al. [58] developed a multi-factor spatial model of forest ecosystem vulnerability to climate change to assess the ecosystem vulnerability of forests and future scenarios of forests under climate change. Modelling forecasting is one of the more popular areas of vulnerability research in recent years.

\subsubsection{Ecological Resilience Evaluation Indicator System}

Since the end of the 20th century, many scholars have explored the factors of ecological resilience, but in general, research on this topic is still lacking, and a consensus concept and model for ecological resilience has not yet been obtained. Therefore, the indicators used for each resilience concept differ in two main ways. First, based on engineering and ecological resilience, the indicators used for assessment reflect state-based indicators, such as forest biodiversity, which is the most used $[59,60]$, as the ability of an ecosystem to remain in an environment that remains unchanged over time related to how quickly it transitions to another environment. Furthermore, Folke et al. [61] show that biodiversity is one of the factors influencing this degree of slowness, in addition to forest structure and function $[62,63]$. The second is based on socio-ecological resilience, mainly stress and response-based indicators, such as population and economy [64]. Overall, indicator systems based on engineering and ecological resilience are the most widely used.

\subsubsection{Ecosystem Vulnerability-Ecological Resilience Indicator Systems}

There is currently no universal ecosystem vulnerability-resilience indicator system, with the IPCC in its Fifth Assessment Report proposing climate vulnerability as a function of exposure, sensitivity to climate change, and resilience or system adaptive capacity [65]. Angeler et al. [66] also showed that assessing system vulnerability by quantifying ecological resilience can help address the uncertainty in predicting ecosystem responses to environmental changes across ecosystems. Additionally, the difficulty of quantifying resilience has been a common challenge encountered by scholars. With the advent of Earth Observation Systems (EOS), satellite remote sensing can quantify resilience in response to disturbances $[67,68]$, but this approach has certain limitations, such as limited spatial resolution, inapplicability to smaller geographical units, and the quantification of ecological resilience for different causes of disturbance does not universally applicable. Overall, further research is needed on the ecosystem vulnerability-resilience indicator system in the future.

\subsection{Technical Method}

3.3.1. Due to the Different Systems of Vulnerability Evaluation Indicators and Data Characteristics, There Are Additionally Many Types of Evaluation Methods, and the Study Needs to Select a Responsive Method for Evaluation According to the Study Scale and the Study Population

Vulnerability evaluation methods mainly include the AHP-fuzzy integrated evaluation method [69], landscape ecology method [70], grey cluster analysis method [71], principal component analysis method [72], set-pair analysis [73], integrated index method [74], and matter element extension method [75]. Among them, the principal component analysis method and the composite index method are widely used, with the former being suitable for quantitative vulnerability evaluation with more complete data and the latter being more widely applicable, mainly by normalizing the data, establishing weights, and then weighting and summing to obtain the vulnerability index. As research progresses, evaluation methods become increasingly diverse and complex. Therefore, when carrying out research, we should select suitable methods for evaluation according to different regional characteristics and research objects to make the results more scientific and credible. 
3.3.2. Ecological Resilience Characterizes the Resistance and Resilience of a System, so Research Methods Need to Be Temporally and Spatially Specific, Which Additionally Means That Simulation Models Must Follow Principles of Applicability and Innovation

Assessing the impacts of environmental change is particularly challenging in forest ecosystems, which are long-lived and often persistent in their response to change [76]. Holling proposed two measures of resilience, the total area of the attraction domain and the height of the lowest point of the attraction basin above the equilibrium point [19]. Carpenter et al. [77] argue that ecological resilience cannot be measured directly and must be estimated by means of resilience surrogates, namely indirect proxies that are derived from theory; in addition, there are rapid assessment methods [78] and threshold analysis methods [76]. However, all these methods and models have certain limitations, and the lack of a suitable model and input explanatory variables can hinder the assessment of true vegetation resilience in complex ecosystems [79]. Therefore, simulation models must follow the principles of applicability and innovation. For example, Duveneck and Scheller [80] considered resistance as a change in species composition over time and used two forest landscape simulation models to simulate forest resilience under three future climate change scenarios and four management regimes, respectively. Additionally, for forest ecosystems to consider resistance and resilience in time and space, Cantarello et al. [81] provided a new quantitative approach using a spatially explicit model of forest dynamics focusing on the three components of resilience, namely resistance, recovery, and net change. New ideas are offered for forest resilience research.

3.3.3. As Ecosystem Vulnerability and Resilience Research Shifts from Mathematical and Theoretical Modelling to "3S" Spatial Analysis, i.e., RS, GIS, and GPS, "3S" Techniques Are Being Used Extensively in the Field of Ecology and the Environment

Vulnerability and resilience research involving multiple domains has a complex structure of research methods and indicator systems. Therefore, the analysis techniques have also changed from the previous mathematical model analysis to "3S" spatial analysis [82]. " $3 S^{\prime}$ " technologies have been widely used in the field of spatial information research, and their application in the field of ecological environment is also developing rapidly. Using " $3 S^{\prime}$ technologies to obtain, process, and dynamically analyze resource and environmental information has become an important trend in the study of fragile ecosystems, and is widely used in ecosystem vulnerability assessment [83]. Sahana and Ganaie [84] analyzed landscape vulnerability in the Rudraprayag region of India based on GIS technology to explore the sensitivity of forests to fire; Hart et al. [85] combined GIS techniques and field trial data to assess the resistance and resilience of eight vegetation species to fire.

\section{Key Scientific Issues to Be Solved}

An extensive survey of the literature shows that significant progress has been made in research on the vulnerability and resilience of forest ecosystems. In general, much of the research has still focused on assessing the vulnerability, response, and future impacts of ecosystems or species to climate change or natural disasters. For example, Perie and de Blois [86] assessed the habitat suitability of tree species and predicted the suitability conditions of species as a function of future climate change, demonstrating that, despite overall regional habitat conditions, the study also demonstrated that different tree species have different adaptive characteristics despite the overall habitat conditions in the region. In contrast, research on forest resilience focuses on assessing the capacity of forest ecosystem composition, structure, and function to both resist and recover from disturbance, and quantifying this capacity through modeling. Seidl et al. [87], for example, propose an approach to disturbance ecology that uses the concept of resilience to quantify and address forest ecosystem services, providing a theoretical basis for the management of constantly disturbed forests. It is worth mentioning that most of the current studies on ecosystem vulnerability and resilience in karst fragile areas are regional large-scale or water resource vulnerability studies, and fewer studies have been conducted on forest ecosystems. In this regard, this paper will raise several scientific questions as follows: 
In view of the problem of less theoretical research. theoretical research on ecosystem vulnerability was mainly at the early stage of qualitative exploration. As ecosystem vulnerability research has matured, theoretical research has become scarcer, and scholars at home and abroad are more likely to conduct ecosystem vulnerability simulation and evaluation of the system, transforming from the previous theoretical research on concepts, causes, and laws to empirical research. Especially with the development of remote sensing technology, technology has become an important data source for ecosystem vulnerability studies. Subsequently, its empirical studies have tended to become more widespread, and in general the development of vulnerability theory studies lags behind the studies of its methodological system. Although ecologically fragile zones have innate ecosystem vulnerability characteristics, with the continuous development of social and economic development, the impact of human interference and other factors on ecologically fragile areas is becoming more and more significant, and the ecological fragility characteristics shown are no longer caused by pure imbalance in the development of the ecological environment itself, but are the result of the superposition of natural and human influences. Therefore, the study of the theoretical system of ecologically fragile areas covers a wide range of contents and should be strengthened in the future under the combined effect of natural and social conditions.

In view of the problem of the lack of unified theoretical norms and evaluation models due to the wide range of evaluation indicators, the complexity and variability of the causes of ecosystem vulnerability have led to a wide range of evaluation indicators and a lack of unified theoretical norms and conceptual models. For forest ecosystems, the causes of vulnerability include internal system factors (community structure and function, etc.), environmental disturbance factors (climate and natural disasters, etc.), and socio-economic (population, income, and livestock situation, etc.). Given the difficulty of quantifying evaluation indicators and the different scales of study, the indicators chosen differ. Some researchers have assessed the vulnerability of forests in different distribution zones by modelling the distribution area of forests and the number of limiting species in order to assess the vulnerability of global forest ecological zones to future climate change [88]. At the same time, some researchers, in order to study the impact of agricultural expansion on forest cover in human-dominated tropical landscapes, have also selected indicators of exposure to cropland expansion, sensitivity, and forest capacity to respond to assess forest vulnerability [89]. Therefore, the indicator system must be selected according to the causes of forest ecosystem vulnerability and the scale of the study. Of course, theoretical research also needs to be strengthened in the future to select appropriate indicators on this basis, and establish a complete, integrated, scientific assessment system of forest ecosystems involving various scales and objects.

In view of the problem of uncertainty in the quantitative evaluation and analysis for ecosystem vulnerability, there are many methods to analyze ecosystem vulnerability, but different climatic factors have different impacts on different ecological factors, and these ecological factors also interact with each other, which together have negative impacts on the ecosystem [90]. Therefore, when conducting a quantitative evaluation of ecosystem vulnerability, a comprehensive analysis of the ecosystem vulnerability characteristics of the study area should be carried out, and the analytical methods and models should be selected in accordance with the principles of scientificity and rationality, to improve the accuracy of the evaluation results.

The current ecosystem vulnerability is limited to large-scale research and lacks clarification from the perspective of small to medium scale and single ecosystem. Due to the booming development of 3S technology, ecosystem vulnerability is mostly limited to large scale studies based on its ability to quickly acquire spatial data [91,92], and there is a lack of clarification of ecosystem vulnerability from the perspective of small and medium scales or single ecosystems issues. Therefore, ecosystem vulnerability studies should be carried out more on small and medium scales, considering the combination of field monitoring and " $3 S^{\prime}$ " technology to obtain experimental data, and to explore in depth the processes, 
characteristics, and mechanisms of fragile ecosystem degradation, to conduct vulnerability assessment. This allows managers to tailor system management strategies to local and situational contexts.

In view of the difficulty of identifying the concept of forest ecological resilience, despite the increasing research on resilience in forest ecosystems, forest resilience is still a vague concept and no resilience concept has been defined or applied in a forestry context to date [30]. Therefore, in the future, we should select a suitable framework of resilience concepts and evaluation indicators based on a recognition of how resilience approaches operate in forest management practice and a clear understanding of how to make resiliencerelated forest management decisions.

The problem of quantifying indicators in resilience evaluation is the biggest difficulty in current research, and exploring the establishment of more accurate mathematical models and the normalization of indicators is a pressing challenge in ecological resilience evaluation research. The required time span and spatial extent make it difficult to reason experimentally about the resilience of forest ecosystems, making simulation models an important tool in research [93]. As research on forest ecological resilience continues, simulation models need to be innovated; for example, Liu et al. [94] used the intensive Landsat time series model to establish forest resilience indicators in order to cope with the maximum magnitude of disturbance to the forest, as a way to quantitatively assess forest resilience. Alternatively, we can quantify forest resilience by selecting appropriate variables. For example, forest ecosystem productivity is a good indicator of ecosystem health, and some forest resilience studies have used normalized tree-ring width index as a state variable [95], while others have used normalized vegetation index, enhanced vegetation indices, and leaf area indices [96-98], all of which are parameters for estimating ecosystem productivity. In conclusion, when conducting forest resilience assessment, it is important to consider the characteristics of the study population and regional features in selecting indicators and building models to improve the rationality and accuracy of the results.

In view of the current lack of a universal framework linking ecosystem vulnerability and resilience, overall, ecological resilience is still mostly focused on studies of socialecological systems such as urban resilience [99], and ecological resilience based on natural ecosystems is less common and mostly independent. Promoting the organic coupling and coordination of ecosystem vulnerability and resilience helps to develop forest conservation strategies and improve forest ecosystem services. Based on the previous discussion, it is known that ecosystem vulnerability characterizes the state, and indicators are easily accessible, while ecological resilience characterizes the process and indicators are difficult to quantify. Therefore, in order to fully grasp the characteristics of forest ecosystems and ensure sustainable development of ecosystems, we can use 3S modelling techniques or a combination of $3 S$ technology and field monitoring to establish a quantitative model linking the vulnerability and resilience of forest ecosystems, considering the selection of indicators from natural, disturbance, and social factors.

Addressing the weak practical application of ecosystem vulnerability and resilience research, ecosystem vulnerability studies can identify key problems in the system, while ecological resilience studies can clarify the resistance and resilience of the system, so that forest managers can apply precise policies to the forest and achieve sustainable management. Ecosystem-based adaptation is seen as having the potential to integrate sustainable management, conservation, and restoration of ecosystems into adaptation to climate change [100]. Therefore, forests in ecologically fragile areas require standardized management and assessment systems that focus on applying theory and practice to maintain ecosystem balance in three ways: firstly, based on research into the vulnerability of forest ecosystems, management policies can be developed to target key vulnerable resources and improve system resilience. Secondly, based on research on habitat suitability of tree species, cultivate plantation forests or introduce new tree species into forest communities to increase forest cover, biodiversity, and system productivity, thereby reducing forest vulnerability and 
increasing resistance to sustainable development. Thirdly, policies should be formulated to reduce anthropogenic disturbances, such as forest closure and reforestation, to improve the resilience of the system.

Addressing the low level of research on the vulnerability and resilience of forest ecosystems in the karst areas, karst rocky desertification represents a relatively unique type of desert in the world [101], and the problem of fragile ecological environment and social development in karst mountain area is an international issue [102]. In response, Xiong et al. proposed a series of vegetation restoration measures for rocky desertification control, including mountain closure [103] and cultivation of ecological and economic forests [104]. However, most of the forests in the region are still vulnerable and less resilient. The reasons are mainly the fragility of the karst itself and the impact of human activities. Therefore, when conducting vulnerability and resilience analyses, the indicators selected should focus on environmental and human disturbance factors. For large scales, $3 S$ technology is used to build a vegetation distribution-anthropogenic activity model, while placing resilience variables (e.g., productivity) in the model to achieve a combination of vulnerability and resilience. For small scales, $3 S$ technology is considered to be combined with field monitoring; community structure and function indicators are added to environmental and anthropogenic factors to accurately identify vulnerable resources in forest ecosystems. In addition, studies can be carried out to assess the vulnerability and sensitivity of species from the perspective of habitat suitability, just as some scholars have used the tree-ring width data to simulate the resistance of the species to drought [9], habitat suitability studies on tree species are particularly important in rocky desertification areas due to the dichotomous structure above and below ground [105] and severe soil erosion. Based on the above studies, we can implement sustainable management policies for karst forests to improve the homogeneous community structure and weak resilience, thus enhancing ecosystem services.

\section{Conclusions and Future Research}

In this paper, we conducted a systematic literature review by analyzing 217 papers retrieved from CNKI and Web of Science. The following conclusions were drawn: (1) research on the vulnerability and resilience of forest ecosystems is rapidly increasing; (2) among the studies on ecosystem vulnerability, ecological resilience, management strategies, and other aspects of forest, ecosystem vulnerability analysis is the most common, accounting for $46.17 \%$, of which vulnerability modeling predictions based on future changes accounts for $9.77 \%$, and is an emerging area for future research; (3) research on forest ecosystem vulnerability and resilience is more widely studied in China and the United States, accounting for $25 \%$ and $18 \%$ of the total, respectively; and (4) most of the research units on forest ecosystem vulnerability and resilience are universities or forestry institutions in developed countries, such as the USA and Germany, with the exception of China.

Following the quantitative analysis, the article also proposes nine key scientific questions to be addressed in response to the current state of research at home and abroad, providing directions for continued in-depth research in the future.

The key questions for future research on the vulnerability and resilience of forest ecosystems can be summarized in the following areas: ecosystem vulnerability and resilience of forests, how to establish a framework for a universally applicable vulnerability indicator system, how to develop models to quantify the resistance and resilience of forest ecosystems, how to link vulnerability and resilience for a comprehensive analysis of forest ecosystems, and how to accurately study forest vulnerability and resilience in the context of rocky desertification control. These are the issues and challenges in urgent need for future research that need to be addressed in the future.

It should be noted here that this paper may be subject to potential uncertainties in the quantitative data of the search results due to the limitations of the search engine, but it has little impact on the subsequent exploration of theoretical advances in forest ecosystem vulnerability and resilience research. 
Author Contributions: K.X. and Y.Y. conceptualized the framework, acquired the funding, and supervised the overall project; H.L., T.L., Y.Q., Z.W. and S.Z. collected data; H.L. analyzed data, and wrote the manuscript; K.X. and Y.Y. provided modification comments; and K.X. and H.L. reviewed the final manuscript. All authors have read and agreed to the published version of the manuscript.

Funding: Funding for the project was supported by the World Top Discipline Program of Guizhou Province (No. 1252019 Qianjiao Keyan Fa), the Key Science and Technology Program of Guizhou Province (No. 54112017 Qiankehe Pingtai Rencai) and the China Overseas Expertise Introduction Program for Discipline Innovation (D17016).

Institutional Review Board Statement: Not applicable.

Informed Consent Statement: Not applicable.

Data Availability Statement: Data are contained within the article.

Conflicts of Interest: The authors declare no conflict of interest.

\section{References}

1. Boonstra, R.; Andreassen, H.P.; Boutin, S.; Hušek, J.; Ims, R.A.; Krebs, C.J.; Skarpe, C.; Wabakken, P. Why do the boreal forest ecosystems of northwestern Europe differ from those of western North America? Bioscience 2016, 66, 722-734. [CrossRef]

2. Millennium Ecosystem Assessment Board. Ecosystems and Human Well-Being; Island Press: Washington, DC, USA, 2005.

3. Miyawaki, A. A vegetation-ecological study on regeneration and restoration of vegetation. Veg. Sci. News 2001, 6, 55-62.

4. Costanza, R.; d'Arge, R.; de Groot, R.; Farber, S.; Grasso, M.; Hannon, B.; Limburg, K.; Naeem, S.; O’Neill, R.V.; Paruelo, J.; et al. The value of the world's ecosystem services and natural capital. Nature 1997, 387, 253-260. [CrossRef]

5. Zemp, D.C.; Schleussner, C.-F.; Barbosa, H.M.J.; Rammig, A. Deforestation effects on Amazon forest resilience. Geophys. Res. Lett. 2007, 44, 6182-6190. [CrossRef]

6. Ozcan, O.; Musaoglu, N.; Tyrkeş, M. Assessing vulnerability of a forest ecosystem to climate change and variability in the western Mediterranean sub-region of Turkey. J. For. Res. 2018, 29, 709-725. [CrossRef]

7. Akinola, O.V.; Adegoke, J. Assessment of forest fire vulnerability zones in Missouri, United States of America. Int. J. Sustain. Dev. World Ecol. 2019, 26, 251-257. [CrossRef]

8. Zimmerman, J.K.; Willig, M.R.; Hernandez-Delgado, E.A. Resistance, resilience, and vulnerability of social-ecological systems to hurricanes in Puerto Rico. Ecosphere 2020, 11, e03159. [CrossRef]

9. $\quad$ Fang, O.; Zhang, Q.B.; Vitasse, Y.; Zweifel, R.; Cherubini, P. The frequency and severity of past droughts shape the drought sensitivity of juniper trees on the Tibetan plateau. For. Ecol. Manag. 2021, 486, 118968. [CrossRef]

10. Kneeshaw, D.D.; Sturtevant, B.R.; DeGrandpé, L.; Doblas-Miranda, E.; James, P.M.A.; Tardif, D.; Burton, P.J. The Vision of Managing for Pest-Resistant Landscapes: Realistic or Utopic? Curr. For. Rep. 2021, 7, 97-113.

11. Truman, C.C.; Strickland, T.C.; Potter, T.L.; Franklin, D.H.; Bosch, D.D.; Bednarz, C.W. Variable rainfall intensity and tillage effects on runoff, sediment, and carbon losses from a loamy sand under simulated rainfall. J. Environ. Qual. 2007, 36, 1495-1502. [CrossRef]

12. Guidi, C.; Di Matteo, G.; Grego, S. An overview of proven Climate Change Vulnerability Assessment tools for forests and forest-dependent communities across the globe: A literature analysis. J. For. Res. 2018, 29, 1167-1175. [CrossRef]

13. De Lange, H.J.; Sala, S.; Vighi, M.; Faber, J.H. Ecological vulnerability in risk assessment-A review and perspectives. Sci. Total Environ. 2010, 408, 3871-3879. [CrossRef] [PubMed]

14. Clements, F.E. Research Methods in Ecology; University Publishing Company: Lincoln, NE, USA, 1905.

15. Niu, W.Y. The discriminatory index with regard to the weakness, overlapness, and breadth of ecotone. Acta Ecol. Sin. 1989, 9 , 97-105.

16. IPCC. Climate Change 2001: Impacts, Adaptation, and Vulnerability; Cambridge University Press: Cambridge, UK; New York, NY, USA, 2001.

17. Turner, B.L.; Kasperson, R.E.; Matson, P.A.; McCarthy, J.J.; Corell, R.W.; Christensen, L.; Eckley, N.; Kasperson, J.X.; Luers, A.; Martello, M.L.; et al. A framework for vulnerability analysis in sustainability science. Proc. Natl. Acad. Sci. USA 2003, 100, 8074-8079. [CrossRef]

18. Shao, Y.W.; Xu, J. Understanding urban resilience: A conceptual analysis based on integrated international literature review. Urban Plan. Int. 2015, 30, 48-54.

19. Holling, C.S. Resilience and Stability of Ecological Systems. Annu. Rev. Ecol. Syst. 1973, 4, 1-23. [CrossRef]

20. Ouyang, H.; Ye, Q. A review on the evolution of resilient city theory: Concept, context and tendency. City Plan. Rev. 2016, 40, 34-42.

21. Gunderson, L.H.; Holling, C.S. (Eds.) Panarchy: Understanding Transformations in Human and Natural Systems; Island Press: Washington, DC, USA, 2002.

22. Liao, K.H. A Theory on Urban Resilience to Floods-A Basis for Alternative Planning Practices. Ecol. Soc. 2012, 17, 48. [CrossRef] 
23. Gann, G.D.; McDonald, T.; Walder, B.; Aronson, J.; Nelson, C.R.; Jonson, J.; Hallett, J.G.; Eisenberg, C.; Guariguata, M.R.; Liu, J.; et al. International Principles and Standards for the Practice of Ecological Restoration. Second edition. Restor. Ecol. 2019, 27, S1-S46. [CrossRef]

24. Ma, X.Y. Spatial Analysis, Evaluation and Optimization of the Yellow River Beach Area in Xinxiang City from the Perspective of Resilient Cities; Beijing Forestry University: Beijing, China, 2019.

25. Keenan, R.J. Climate change impacts and adaptation in forest management: A review. Ann. For. Sci. 2015, 72, 145-167. [CrossRef]

26. Lucier, A.; Ayres, M.; Karnosky, D.; Thompson, I.; Loehle, C.; Percy, K.; Sohngen, B. Forest responses and vulnerabilities to recent climate change. IUFRO World Ser. 2009, 22, 29-52.

27. De La Serrana, R.G.; Vilagrosa, A.; Alloza, J.A. Pine mortality in southeast Spain after an extreme dry and warm year: Interactions among drought stress, carbohydrates and bark beetle attack. Trees 2015, 29, 1791-1804. [CrossRef]

28. Bernier, P.; Schoene, D. Adapting Forests and Their Management to Climate Change: An Overiew; Information Service of FAO: Rome, Italy, 2009; Volume 60, pp. 5-11.

29. Hou, K.; Tao, W.; Wang, L.; Li, X.X. Study on hierarchical transformation mechanisms of regional ecological vulnerability and its applicability. Ecol. Indic. 2020, 114, 106343. [CrossRef]

30. Nikinmaa, L.; Lindner, M.; Cantarello, E.; Jump, A.S.; Seidl, R.; Winkel, G.; Muys, B. Reviewing the use of resilience concepts in forest sciences. Curr. For. Rep. 2020, 6, 61-80. [CrossRef]

31. Lecina-Diaz, J.; Martinez-Vilalta, J.; Alvarez, A.; Banque, M.; Birkmann, J.; Feldmeyer, D.; Vayredm, J.; Retana, J. Characterizing forest vulnerability and risk to climate-change hazards. Front. Ecol. Environ. 2021, 19, 126-133. [CrossRef]

32. Reyer, C.P.O.; Brouwers, N.; Rammig, A.; Brook, B.W.; Epila, J.; Grant, R.F.; Holmgren, M.; Langerwisch, F.; Leuzinger, S.; Lucht, W.; et al. Forest resilience and tipping points at different spatio-temporal scales: Approaches and challenges. J. Ecol. 2015, 103, 5-15. [CrossRef]

33. Weißhuhn, P.; Müller, F.; Wiggering, H. Ecosystem vulnerability review: Proposal of an interdisciplinary ecosystem assessment approach. Environ. Manag. 2018, 61, 904-915. [CrossRef]

34. Rana, I.A. Disaster and climate change resilience: A bibliometric analysis. Int. J. Disaster Risk Reduct. 2020, 50, 101839. [CrossRef]

35. Kumar, M.; Kalra, N.; Singh, H.; Sharma, S.; Singh Rawat, P.; Singh, R.K.; Gupta, A.K.; Jumar, P.; Ravindranath, N.H. Indicatorbased vulnerability assessment of forest ecosystem in the Indian Western Himalayas: An analytical hierarchy process integrated approach. Ecol. Indic. 2021, 125, 107568. [CrossRef]

36. Johnstone, J.F.; Allen, C.D.; Franklin, J.F.; Frelich, L.E.; Harvey, B.J.; Higuera, P.E.; Mack, M.C.; Meentemeyer, R.K.; Metz, M.R.; Perry, G.L.W.; et al. Changing disturbance regimes, ecological memory, and forest resilience. Front. Ecol. Environ. 2016, 14, 369-378. [CrossRef]

37. Ibarra, J.T.; Cockle, K.; Altamirano, T.; van der Hoek, Y.; Simard, S.W.; Bonacic, C.; Martin, K. Nurturing resilient forest biodiversity: Nest webs as complex adaptive systems. Ecol. Soc. 2020, 25, 27. [CrossRef]

38. Timmerman, P. Vulnerability, Resilience and the Collapse of Society: A Review of Models and Possible Climatic Applications; Institute for Environmental Studies, University of Toronto: Toronto, ON, Canada, 1981.

39. Gong, W.; Hu, T.X.; Gong, Y.B. A brief discussion on the formation characteristics of fragile forest ecosystems and their management measures. Sichuan For. Explor. Des. 2004, 3, 5-10.

40. Schelhaas, M.J.; Hengeveld, G.; Moriondo, M.; Reinds, G.J.; Kundzewicz ter Maat, H.W.; Bindi, M. Assessing risk and adaptation options to fires and windstorms in European forestry. Mitig. Adapt. Strateg. Glob. Chang. 2010, 15, 681-701. [CrossRef]

41. Mildrexler, D.J.; Yang, Z.; Cohen, W.; Bell, D. A forest vulnerability index based on drought and high temperatures. Remote Sens. Environ. 2016, 173, 314-325. [CrossRef]

42. Peng, Q.; Lin, C.H.; He, T.F. The development of study on the characteristics of soil and water loss and its conservation in Guizhou karst mountain area. Guizhou Sci. 2006, 24, 66-70.

43. Ali, A. Climate change impacts and adaptation assessment in Bangladesh. Clim. Res. 1999, 12, 109-116. [CrossRef]

44. Chuluundorj, O. A Multi-Level Study of Vulnerability of Mongolian Pastoralists to Natural Hazards and Its Consequences on Individual and Household Well-Being; University of Colorado: Denver, CO, USA, 2006.

45. Bone, C.; Moseley, C.; Vinyeta, K.; Bixler, R.P. Employing resilience in the United States forest service. Land Use Policy 2016, 52, 430-438. [CrossRef]

46. Pimm, S.L. The complexity and stability of ecosystems. Nature 1984, 307, 321-326. [CrossRef]

47. Hodgson, D.; McDonald, J.L.; Hosken, D.J. What do you mean, 'resilient'? Trends Ecol. Evol. 2015, 30, 503-506. [CrossRef] [PubMed]

48. Thompson, I.; Mackey, B.; McNulty, S.; Mosseler, A. Forest Resilience, Biodiversity and Climate Change: A Synthesis of the Biodiversity/Resilience/Stability Relationship in Forest Ecosystems; Technical Series no. 43; Secretariat of the Convention on Biological Diversity: Montreal, QC, Canada, 2009; pp. 1-67.

49. Law, B.E.; Waring, R.H. Carbon implications of current and future effects of drought, fire and management on Pacific Northwest forests. For. Ecol. Manag. 2015, 355, 4-14. [CrossRef]

50. Huang, M.; Wang, X.; Keenan, T.F.; Piao, S. Drought timing influences the legacy of tree growth recovery. Glob. Chang. Biol. 2018, 24, 3546-3559. [CrossRef]

51. Brown, E.D.; Williams, B.K. Resilience and resource management. Environ. Manag. 2018, 56, 1416-1427. [CrossRef] [PubMed]

52. Yu, B.H.; Lu, C.H. Assessment of ecological vulnerability on the Tibetan plateau. Geogr. Res. 2011, 30, $2289-2295$. 
53. Berger, A.R.; Hodge, R.A. Natural change in the environment: A challenge to the pressure-state-response concept. Soc. Indic. Res. 1998, 44, 255-265. [CrossRef]

54. Polsky, C.; Neff, R.; Yarnal, B. Building comparable global change vulnerability assessments:The vulnerability scoping diagram. Glob. Environ. Chang. Hum. Policy Dimens. 2007, 17, 472-485. [CrossRef]

55. Cinco-Castro, S.; Herrera-Silveira, J. Vulnerability of mangrove ecosystems to climate change effects: The case of the Yucatan Peninsula. Ocean Coast. Manag. 2020, 192, 105196. [CrossRef]

56. Wang, J.Y.; Zhao, G.X.; Wang, X.F.; Wang, L.H.; Liu, M.S.; Liu, T. On the vulnerability of China's ecological environment and its assessment. Shandong Agric. Sci. 2004, 2, 9-11.

57. Xu, G.C.; Kang, M.Y.; He, L.N.; Li, Y.F.; Chen, Y.R. Advance in research on ecological vulnerability. Acta Ecol. Sin. 2009, 29, 2578-2588.

58. Turkes, M.; Musaoglu, N.; Ozcan, O. Assessing the vulnerability of a forest ecosystem to climate change and variability in the western Mediterranean sub-region of Turkey: Future Evaluation. J. For. Res. 2018, 29, 1177-1186. [CrossRef]

59. Derroire, G.; Balvanera, P.; Castellanos-Castro, C.; Decocq, G.; Kennard, D.K.; Lebrija-Trejos, E.; Leiva, J.A.; Oden, P.-C.; Powers, J.S.; Rico-Gray, V.; et al. Resilience of tropical dry forests-a meta-analysis of changes in species diversity and composition during secondary succession. Oikos 2016, 125, 1386-1397. [CrossRef]

60. Lennox, G.D.; Gardner, T.A.; Thomson, J.R.; Ferreira, J.; Berenguer, E.; Lees, A.C.; Nally, R.M.; Aragao, L.E.O.C.; Ferraz, S.F.B.; Louzada, J.; et al. Second rate or a second chance? Assessing biomass and biodiversity recovery in regenerating Amazonian forests. Glob. Chang. Biol. 2018, 24, 5680-5694. [CrossRef] [PubMed]

61. Folke, C.; Carpenter, S.; Walker, B.; Scheffer, M. Regime shifts, resilience, and biodiversity in ecosystem management. Annu. Rev. Ecol. Evol. Syst. 2004, 35, 557-581. [CrossRef]

62. Craven, D.; Filotas, E.; Angers, V.A.; Messier, C. Evaluating resilience of tree communities in fragmented landscapes: Linking functional response diversity with landscape connectivity. Divers. Distrib. 2016, 22, 505-518. [CrossRef]

63. López-Jiménez, L.N.; Duran-Garcia, R.; Dupuy-Rada, J.M. Recovery of structure, diversity and composition of a tropical semievergreen forest in Yucatan, Mexico. Madera Bosques 2019, 25, e2511587.

64. Rivera-Monroy, V.H.; Danielson, T.M.; Castañeda-Moya, E.; Marx, B.D.; Travieso, R.; Zhao, X.; Gaiser, E.E.; Farfan, L.M. Long-term demography and stem productivity of Everglades mangrove forests (Florida, USA): Resistance to hurricane disturbance. For. Ecol. Manag. 2019, 440, 79-91. [CrossRef]

65. IPCC. Climate Change 2014: Impacts, Adaptation, and Vulnerability; Cambridge University Press: Cambridge, UK, 2014.

66. Angeler, D.G.; Baho, D.L.; Allen, C.R.; Johnson, R.K. Linking degradation status with ecosystem vulnerability to environmental change. Oecologia 2015, 178, 899-913. [CrossRef] [PubMed]

67. Cui, X.; Gibbes, C.; Southworth, J.; Waylen, P. Using remote sensing to quantify vegetation change and ecological resilience in a semi-arid system. Land 2013, 2, 108-130. [CrossRef]

68. Dwomoh, F.K.; Wimberly, M.C. Fire regimes and forest resilience: Alternative vegetation states in the West African tropics. Landsc. Ecol. 2017, 32, 1849-1865. [CrossRef]

69. Li, J.D.; Xu, D. Evaluation on exploitation potential of forest health tourism based on AHP and fuzzy synthetic evaluation-A case study of Liaodong mountain area. Chin. J. Agric. Resour. Reg. Plan. 2018, 39, 135-142.

70. Giglio, E. Landscape ecological method to study agriculture vegetation: Some examples from the po valley. Ann. Bot. 2016, 6 , 95-110.

71. Delgado, A.; Vidal, J.; Castro, J.; Felix, J.; Saenz, J. Assessment of Surface Water Quality on the Upper Watershed of Huallaga River, in Peru, using Grey Systems and Shannon Entropy. Int. J. Adv. Comput. Sci. Appl. 2020, 11, 437-444. [CrossRef]

72. Xenarios, S.; Nemes, A.; Sarker, G.W.; Nagothu, U.S. Assessing vulnerability to climate change: Are communities in flood-prone areas in Bangladesh more vulnerable than those in drought-prone areas? Water Resour. Rural Dev. 2016, 7, 1-19. [CrossRef]

73. Li, B.; Yang, Z.; Su, F. Vulnerability measurement of Chinese marine economic system based on set pair analysis. Sci. Geogr. Sin. 2016, 36, 47-54.

74. Wirehn, L.; Danielsson, A.; Neset, T.-S.S. Assessment of composite index methods for agricultural vulnerability to climate change. J. Environ. Manag. 2015, 156, 70-80. [CrossRef]

75. Huang, Z.; Wan, J. Vulnerability assessment of safe operation of utility tunnel based on improved matter-element extension method. Constr. Sci. Technol. 2020, 8, 78-81.

76. Standish, R.J.; Hobbs, R.J.; Mayfield, M.M.; Bestelmeyer, B.; Suding, K.N.; Battaglia, L.; Eviner, V.T.; Hawkes, C.V.; Temperton, V.M.; Harris, V.A.C.J. Resilience in ecology: Abstraction, distraction, or where the action is? Biol. Conserv. 2014, $177,43-51$. [CrossRef]

77. Carpenter, S.R.; Westley, F.; Turner, M.G. Surrogates for resilience of social-ecological systems. Ecosystems 2005, 8, 941-944. [CrossRef]

78. Nemec, K.T.; Chan, J.; Hoffman, C.; Spanbauer, T.L.; Hamm, J.A.; Allen, C.R.; Hefley, T.; Pan, D.; Shrestha, P. Assessing resilience in stressed watersheds. Ecol. Soc. 2014, 19, 34. [CrossRef]

79. Behera, M.D.; Murthy, M.S.R.; Das, P.; Sharma, E. Modelling forest resilience in Hindu Kush Himalaya using geoinformation. J. Earth Syst. Sci. 2018, 127, 95. [CrossRef]

80. Duveneck, M.J.; Scheller, R.M. Measuring and managing resistance and resilience under climate change in northern Great Lake forests (USA). Landsc. Ecol. 2016, 31, 669-686. [CrossRef] 
81. Cantarello, E.; Newton, A.C.; Martin, P.A.; Evans, P.M.; Gosal, A.; Lucash, M.S. Quantifying resilience of multiple ecosystem services and biodiversity in a temperate forest landscape. Ecol. Evol. 2017, 7, 9661-9675. [CrossRef] [PubMed]

82. Zhang, X.L.; Yu, W.B.; Cai, H.S.; Guo, X.M. Review of the evaluation methods of regional eco-environmental vulnerability. Acta Ecol. Sin. 2018, 38, 5970-5981.

83. Fang, C.; Wang, Y.; Fang, J. A comprehensive assessment of urban vulnerability and its spatial differentiation in China. J. Geogr. Sci. 2016, 26, 153-170. [CrossRef]

84. Sahana, M.; Ganaie, T.A. GIS-based landscape vulnerability assessment to forest fire susceptibility of Rudraprayag district, Uttarakhand, India. Environ. Earth Sci. 2017, 76, 676. [CrossRef]

85. Hart, S.J.; Henkelman, J.; McLoughlin, P.D.; Nielsen, S.E.; Truchon-Savard, A.; Johnstone, J.F. Examining forest resilience to changing fire frequency in a fire-prone region of boreal forest. Glob. Chang. Biol. 2019, 25, 869-884. [CrossRef]

86. Perie, C.; de Blois, S. Dominant forest tree species are potentially vulnerable to climate change over large portions of their range even at high latitudes. Peer J. 2016, 4, e2218. [CrossRef]

87. Seidl, R.; Spies, T.A.; Peterson, D.L.; Stephens, S.L.; Hicke, J.A. Searching for resilience: Addressing the impacts of changing disturbance regimes on forest ecosystem services. J. Appl. Ecol. 2016, 53, 120-129. [CrossRef]

88. Wang, C.J.; Zhang, Z.X.; Wan, J.Z. Vulnerability of global forest ecoregions to future climate change. Glob. Ecol. Conserv. 2019, 20, e00760. [CrossRef]

89. Bourgoin, C.; Oszwald, J.; Bourgoin, J.; Gond, V.; Blanc, L.; Dessard, H.; Van Phan, T.; Sist, P.; Laderach, P.; Reymondin, L. Assessing the ecological vulnerability of forest landscape to agricultural frontier expansion in the Central Highlands of Vietnam. Int. J. Appl. Earth Obs. Geoinf. 2020, 84, 101958. [CrossRef]

90. Prentice, I.C.; Cramer, W.; Harrison, S.P.; Leemans, R.; Monserud, R.A.; Solomon, A.M. A global biome model based on plant physiology and dominance, soil properties and climate. J. Biogeogr. 1992, 19, 117-134. [CrossRef]

91. Guo, B.; Zang, W.; Luo, W. Spatial-temporal shifts of ecological vulnerability of Karst Mountain ecosystem-impacts of global change and anthropogenic interference. Sci. Total Environ. 2020, 741, 140256. [CrossRef]

92. Hu, W.J.; Chen, B.; Arnupap, P.; Zhang, D.; Liu, X.M.; Gu, H.F.; Ajcharaporn, P.; Chao, B.X.; Zheng, X.Q. Ecological vulnerability assessment of coral reef: A case study of Si Chang island, Thailand. Chin. J. Ecol. 2020, 39, 979-989.

93. Albrich, K.; Rammer, W.; Turner, M.G.; Ratajczak, Z.; Brazinuas, K.H.; Hansen, W.D.; Seidl, R. Simulating forest resilience: A review. Glob. Ecol. Biogeogr. 2020, 29, 2082-2096. [CrossRef] [PubMed]

94. Liu, M.; Liu, X.; Wu, L.; Tang, Y.; Li, Y.; Zhang, Y.; Ye, L.; Zhang, B. Establishing forest resilience indicators in the hilly red soil region of southern China from vegetation greenness and landscape metrics using dense Landsat time series. Ecol. Indic. 2021, 121, 106985. [CrossRef]

95. Gao, S.; Liu, R.; Zhou, T.; Fang, W.; Yi, C.; Lu, R.; Luo, H. Dynamic responses of tree-ring growth to multiple dimensions of drought. Glob. Chang. Biol. 2018, 24, 5380-5390. [CrossRef]

96. Di Mauro, B.; Fava, F.; Busetto, L.; Crosta, G.F.; Colombo, R. Post-fire resilience in the Alpine region estimated from MODIS satellite multispectral data. Int. J. Appl. Earth Obs. Geoinf. 2014, 32, 163-172. [CrossRef]

97. Spasojevic, M.J.; Bahlai, C.A.; Bradley, B.A.; Butterfield, B.J.; Tuanmu, M.N.; Sistla, S.; Suding, K.N. Scaling up the diversityresilience relationship with trait databases and remote sensing data: The recovery of productivity after wildfire. Glob. Chang. Biol. 2016, 22, 1421-1432. [CrossRef]

98. Danielson, T.M.; Rivera-Monroy, V.H.; Castañeda-Moya, E.; Briceño, H.; Travieso, R.; Marx, B.D.; Farfán, L.M. Assessment of Everglades mangrove forest resilience: Implications for above-ground net primary productivity and carbon dynamics. For. Ecol. Manag. 2017, 404, 115-125. [CrossRef]

99. Wu, X.; Zhang, J.; Geng, X.; Wang, T.; Wang, K.; Liu, S. Increasing green infrastructure-based ecological resilience in urban systems: A perspective from locating ecological and disturbance sources in a resource-based city. Sustain. Cities Soc. 2020, 61, 102354. [CrossRef]

100. IUCN. Ecosystem-Based Adaptation: An Approach for Building Resilience and Reducing Risk for Local Communities and Ecosystems. Submission to the Chair of the AWG-LCA with respect to the Shared Vision and Enhanced Action on Adaptation; International Union for the Conservation of Nature: Grand, Switzerland, 2008.

101. Yang, M.D. On the fragility of karst environment. Yunnan Geogr. Environ. Res. 1990, 2, 21-29.

102. Ouyang, Z.Y. On the comprehensive management, development and breaking away from poorness of the ecologically fragile karst area in south-west China. World Sci.-Tech. R. D. 1998, 2, 3-5.

103. Xiong, K.N.; Li, P.; Zhou, Z.F. A Typical Study on Remote Sensing-GIS of Karst Desertification in Guizhou Province; Geological Publishing House: Beijing, China, 2002; pp. 128-150.

104. Xiong, K.N.; Mei, Z.M.; Peng, X.W.; Lan, A.J. Integrated management of the karst rock desertification areas-A case study of Huangjiang karst gorge. Guizhou For. Sci. Technol. 2006, 1, 5-8.

105. Yang, M.D. On the geographical structure of karst landscapes and their environmental effects. Guizhou Soc. Environ. Sci. 1998, 11, e03159. 